\section{A Possible Pathway from Stress to Fibrosis}

\author{
Pernille Thomsen* \\ Physiotherapist, External Lector at the Faculty of Physiotherapy, Pernille- \\ fys.dk, Copenhagen, Denmark
}

\section{Commentary}

Stress and related diseases such as depression and anxiety are increasing rapidly in the Western world. In 2011, WHO predicted that depression would be the leading cause of disease burden globally in 2030 [1]. Stress reactions are detected all the way from early childhood, adolescents up to grown- ups and elderly. The reactions are distributed across all socio-economic layers, but more common for low and middle socioeconomic status [1].

The status in Denmark in 2018 was that $15.5 \%$ of all females and 10, 9 of all men had poor mental health. In 2011 The Danish board of health documented that $23 \%$ of the girls and $17 \%$ of the boys, $11-15$ years of age, failed to thrive [2].

In my physiotherapy praxis, I work with children and adolescents age 6-18 that fail to thrive. They are normal children without any psychiatric diagnose. They are referred to me with psychosomatic issues such as poor sleep, muscle aches, headaches, bowel problems, palpitations, tremors, and poor concentration. These symptoms could be the same as we see regarding ADHD, but they don't fall into that category. I started working with these children six years ago, together with a child psychologist. Our focus is looking at these children in a bio-psyco-social perspective. The Child psychologist is focussing on the psyco-social part, and I focus on the neuroscience behind stress and failing to thrive.

Stress can be described in many ways. As a physiotherapist, I have looked into the neurobiological consequences. Stress is an activation of the sympathetic nervous system over time. When life feels overwhelming, the amygdala turns on the hypothalamus and the sympathetic nervous system. The sympathetic nervous system releases both adrenalin and nor-adrenalin. Slavich and Irwing [3] have pointed out that loneliness, social exclusion, and social evaluation can activate the sympathetic nervous system.

*Corresponding author: Pernille Thomsen, Physiotherapist, External Lector a the Faculty of Physiotherapy, Pernillefys.dk, Copenhagen, Denmark, Tel: +45 40503939; E-mail: pernillefys@gmail.com

Citation: Thomsen P (2019) A Possible Pathway from Stress to Fibrosis. J Phys Med Rehabil Disabil 5: 032.

Received: April 08, 2019; Accepted: May 21, 2019; Published: May 28, 2019

Copyright: $\odot 2019$ Thomsen P. This is an open-access article distributed under the terms of the Creative Commons Attribution License, which permits unrestricted use, distribution, and reproduction in any medium, provided the original author and source are credited.
Adrenalin is felt in the body at once - it makes your heart beat faster, the breathing more shallow, may be you feel tingling in fingers or face, your mouth gets dry and you may feel nausea. This is not a problem over a short period of time, but if it continues, nor-adrenalin will affect the secretion of pro and anti-inflammatory cytokines [3] over time stress will lead to chronic low-grade inflammation [4]. TGF-beta 1 is one of the cytokines that are released, I will return to TGF beta 1 later in this thesis, because of the link to the connective tissue.

Furthermore, the adrenals release cortisol. Cortisol is not dangerous over a short period of time, but sustained cortisol release will affect the hippocampus area in the brain. The consequences are so severe that center on the developing child, calls it toxic brain [5]. Uncontrollable stress has been recognized to influence the hippocampus at various levels, structurally, human and animal studies have shown that stress changes neuronal morphology, suppresses neuronal proliferation, and reduces hippocampal volume [6].

Furthermore sympathetic activation over time will reduce the blood supply to the frontal lobes and the bowel. The hippocampal atrophy and the reduced blood flow to the frontal lobes can explain the changes in emotional regulation, concentration, and executive functions. The sympathetic nervous system affecting blood flow to the bowel can also be part of the explanation regarding bowel problems [7].

As a physiotherapist, I also hear a lot about headaches and muscular skeletal pain. Some of this can be explained by the startle response. In 2017 Dr. Alfven [8] published research regarding the startle response in children with chronic stress-induced recurrent muscle pain (He concluded that).

For the first time in children with recurrent psychosomatic pain, increased resting activity, and potentiated startle response were demonstrated in the muscles involved in the stress tender point pattern [8]. The tender points in the muscles responsible for the startle reaction could explain headache and other musculoskeletal problems. The children and adolescents i see also tell me about feeling stiff in the muscles - something many adults also describe when their sympathetic nervous system is overloaded.

There is no evidence-based link between "Stress and feeling stiff", but a possible pathway could be looking into one of the cytokines that are released - TGF Beta 1. Before describing the possible pathway, it's important to understand the physiology and function of the loose connective tissue. The terminology regarding fascia and loose connective tissue is still under debate and has been discussed in the last 12 years which is a very unsatisfactory situation. The Fascia research Society tried to define fascia in 2015 [9].

The latest definition regarding fascia is from 2017; "The fascial system consists of the three-dimensional continuum of soft collagencontaining loose and dense fibrosis connective tissues that permeate the body..." and "the fascial system surrounds interweaves between, and interpenetrates all organs, muscles, bones and nerve fibres, 
endowing the body with a functional structure, and providing an environment that enables all body systems to operate in an integrated matter" [10].

As Kumka expresses it "Fascia is an innervated continues organ of stability and motion" [11]. The physiology of the loose connective tissue is very well described in "Fascial Dysfunction, the Manuel approaches" [10]. One of the important roles of the loose connective tissue is that it allows movement such as sliding, gliding function between adjacent structures.

The loose connective tissue is built by Extracellular Matrix (ECM) and cells. The cells are primarily fibroblast, collagen, and elastin. Albeiroti, et al., [12] describes; "Fibroblasts activated by cytokines or growth factors differentiate into myofibroblasts that drive fibrosis by depositing ECM molecules, such as collagen, fibronectin and connective tissue growth factor. Transforming Growth Factor- (TGF-Beta) is one of the major profibrotic cytokines which promotes fibrosis by signaling abnormal ECM regulation. Hyaluronan (HA) is a major ECM glycosaminoglycan that is regulated by TGF- beta and whose role in fibrosis is emerging." Furthermore, Albeiroti, et al., describes that "Aside from its role as a hydrating, space-filling polymer, HA regulates different cellular functions and is known to have a role in wound healing and inflammation" [12].

Dr. Stecco and Dr. Raghavan [13] have also described the role of Hyaluronan regarding movement. They have found that inactivity makes Hyaluronan aggregate. The consequence is that the loose connective tissue will act like glue instead of oil, making adjacent structures stick to each other - all the way up to densification.

Furthermore, the fibroblast will turn into a myofibroblast and have a contractile force in the fascia - when affected by the sympathetic nervous system $[14,15]$. Back to my children and adolescents that are feeling stiff. As described, stress will lead to a chronic low grade of inflammation and secretion of TGF beta 1.[3,4] TGF beta 1 is one of the main drivers of fibrosis [12], changing the viscoelastic properties of hyaluronan in the extracellular matrix - making adjacent structures stick together [13]. The possible pathway from stress and negative emotions to fibrosis could look like this. This figure 1 shows how the pathway could be. When a person's sympathetic nervous system is activated over a period of time, science shows that cytokines are released $[3,4]$. One of the cytokines that are released is TGF Beta 1. We also know that TGF Beta 1 is one of the key factors in fibrosis $[10,12,13]$. Combining these facts, that stress/an overactive sympathetic nervous system over time and TGF Beta 1 as a key-player in fibrosis, could lead to a conclusion that there is a biomechanical connection between stress and fibrosis.

The conclusion could be that there is a biomechanical connection between stress/and overactive sympathetic nervous system over time and fibrosis. The connection could be the cytokine TGF Beta 1, that are released by the sympathetic nervous system and also plays a key role I fibrosis.

The perspective in this hypothesis is that when you are feeling stiff, maybe you should start by looking at how you are feeling; is your sympathetic nervous system driving too hard? Do you have trouble sleeping, do you get infections more often, and do you have bowel problems, problems concentrating, palpitations, shallow breathing, tickling, nausea or tunnel vision.

\section{The Possible Pathway from Stress and Negative Emotions to Fibrosis}

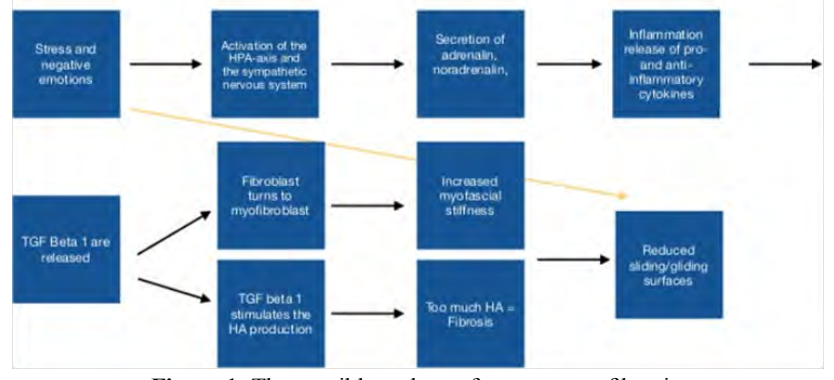

Figure 1: The possible pathway from stress to fibrosis.

Another interesting observation regarding the loose connective tissue is that it contains a lot of interoceptors [14,15]. Interoceptors are part of our sensory system that gives us the opportunity to feel our selves. Many of my patients tell me "It's like I can't feel myself anymore" - maybe there is a connection between aggregated, stiff loose connective tissue and how it affects our interoception?

I have been asked do an RCT on this hypothesis - but how do you randomize how your feelings affect you? I don't know, because like everything else in life - it's individual.

\section{References}

1. https:/www.who.int/mental_health/management/depression/ wfmh_paper_depression_wmhd_2012.pdf.

2. https://www.sst.dk/da/sundhed-og-livsstil/mental-sundhed

3. Slavich GM, Irwin MR (2014) From stress to inflammation and major depressive disorder: a social signal transduction theory of depression. Psychol Bull 140: 774-815.

4. Gouin JP, Hantsoo LV, Kiecolt-Glaser JK (2011) Stress, Negative Emotions and Inflammation. Chap 54, Oxford Handbook of Social Neuroscience.

5. https://developingchild.harvard.edu

6. Kim EJ, Pellman B, Kim JJ (2015) Stress effects on the Hippocampus: a critical review. Learn men 22: 411-416.

7. Mazur M, Furgała A, Jabłoński K, Mach T, Thor P (2012) Autonomic nervous system activity in constipation-predominant irritable bowel syndrome patients. Med Sci Monit 18: 493-499.

8. Alfvén G, Grillner S, Andersson E (2017) Children with chronic stress-induced recurrent muscle pain have enhanced startle reaction. European Journal of Pain 21: 1561-1570.

9. https://fasciaresearchsociety.org

10. Chaitow L (2018) Fascial Dysfunction: Manual Therapy approaches. $\left(2^{\text {nd }}\right)$ edn, Handspring publishing, Edinburgh, UK.

11. Kumka M, Bonar B (2012) Fascia: a morphological description and classification system based on a literature review. Can Chiropr Assoc 56: 179191.

12. Albeiroti S, Soroosh A, de la Motte C (2015) Hyaluronan's Role in Fibrosis: A Pathogenic Factor or a Passive Player. Biomed Res Int. 
13. Cowman MK, Schmidt TA, Raghavan P, Stecco A (2015) Viscoelastic Properties of Hyaluronan in Physiological Conditions. F100Res 25: 4:622.

14. Schleip R (2017) Fascia as a sensory organ: Clinical Applications. Terra rosa e-mag 20: 2-7.
15. Schleip R, Jäger H, Klingler W (2012) Fascia is alive. Fascia the tensional network of the human body. In: Schelip R, Findley TW, Chaitow L, Huijing PA (eds.). Elsevier, Pg no: 157-164. 


\section{Hit \\ HERALD}

Journal of Anesthesia \& Clinical Care

Journal of Addiction \& Addictive Disorders

Advances in Microbiology Research

Advances in Industrial Biotechnology

Journal of Agronomy \& Agricultural Science

Journal of AIDS Clinical Research \& STDs

Journal of Alcoholism, Drug Abuse \& Substance Dependence

Journal of Allergy Disorders \& Therapy

Journal of Alternative, Complementary \& Integrative Medicine

Journal of Alzheimer's \& Neurodegenerative Diseases

Journal of Angiology \& Vascular Surgery

Journal of Animal Research \& Veterinary Science

Archives of Zoological Studies

Archives of Urology

Journal of Atmospheric \& Earth-Sciences

Journal of Aquaculture \& Fisheries

Journal of Biotech Research \& Biochemistry

Journal of Brain \& Neuroscience Research

Journal of Cancer Biology \& Treatment

Journal of Cardiology \& Neurocardiovascular Diseases

Journal of Cell Biology \& Cell Metabolism

Journal of Clinical Dermatology \& Therapy

Journal of Clinical Immunology \& Immunotherapy

Journal of Clinical Studies \& Medical Case Reports

Journal of Community Medicine \& Public Health Care

Current Trends: Medical \& Biological Engineering

Journal of Cytology \& Tissue Biology

Journal of Dentistry: Oral Health \& Cosmesis

Journal of Diabetes \& Metabolic Disorders

Journal of Dairy Research \& Technology

Journal of Emergency Medicine Trauma \& Surgical Care

Journal of Environmental Science: Current Research

Journal of Food Science \& Nutrition

Journal of Forensic, Legal \& Investigative Sciences

Journal of Gastroenterology \& Hepatology Research

Journal of Gerontology \& Geriatric Medicine

Journal of Genetics \& Genomic Sciences

Journal of Hematology, Blood Transfusion \& Disorders

Journal of Human Endocrinology

Journal of Hospice \& Palliative Medical Care

Journal of Internal Medicine \& Primary Healthcare

Journal of Infectious \& Non Infectious Diseases

Journal of Light \& Laser: Current Trends

Journal of Modern Chemical Sciences

Journal of Medicine: Study \& Research

Journal of Nanotechnology: Nanomedicine \& Nanobiotechnology

Journal of Neonatology \& Clinical Pediatrics

Journal of Nephrology \& Renal Therapy

Journal of Non Invasive Vascular Investigation

Journal of Nuclear Medicine, Radiology \& Radiation Therapy

Journal of Obesity \& Weight Loss

Journal of Orthopedic Research \& Physiotherapy

Journal of Otolaryngology, Head \& Neck Surgery

Journal of Protein Research \& Bioinformatics

Journal of Pathology Clinical \& Medical Research

Journal of Pharmacology, Pharmaceutics \& Pharmacovigilance

Journal of Physical Medicine, Rehabilitation \& Disabilities

Journal of Plant Science: Current Research

Journal of Psychiatry, Depression \& Anxiety

Journal of Pulmonary Medicine \& Respiratory Research

Journal of Practical \& Professional Nursing

Journal of Reproductive Medicine, Gynaecology \& Obstetrics

Journal of Stem Cells Research, Development \& Therapy

Journal of Surgery: Current Trends \& Innovations

Journal of Toxicology: Current Research

Journal of Translational Science and Research

Trends in Anatomy \& Physiology

Journal of Vaccines Research \& Vaccination

Journal of Virology \& Antivirals

Archives of Surgery and Surgical Education

Sports Medicine and Injury Care Journal

International Journal of Case Reports and Therapeutic Studies 